University of Rhode Island

DigitalCommons@URI

Open Access Master's Theses

1986

\title{
The Effect of Geographic Mobility on Selected Psychological Variables in Eighth and Ninth Grade Students
}

David C. Marsh

University of Rhode Island

Follow this and additional works at: https://digitalcommons.uri.edu/theses

\section{Recommended Citation}

Marsh, David C., "The Effect of Geographic Mobility on Selected Psychological Variables in Eighth and Ninth Grade Students" (1986). Open Access Master's Theses. Paper 1650.

https://digitalcommons.uri.edu/theses/1650

This Thesis is brought to you for free and open access by DigitalCommons@URI. It has been accepted for inclusion in Open Access Master's Theses by an authorized administrator of DigitalCommons@URI. For more information, please contact digitalcommons-group@uri.edu. 
THE EFFECT OF GEOGRAPHIC MOBILITY ON SELECTED

PSYCHOLOGICAL VARIABLES IN EIGHTH

AND NINTH GRADE STUDENTS

BY

DAVID C. MARSH

A THESIS SUBMITTED IN PARTIAL FULFILLMENT OF THE REQUIREMENTS FOR THE DEGREE OF

MASTER OF SCIENCE

IN

PHYSICAL EDUCATION

UNIVERSITY OF RHODE ISLAND

1986 


\section{ABSTRACT}

This study was conducted to better identify psychological variables, particularly sport specific psychological variables, which are associated with geographic mobility. Geographic mobility was defined both as distance moved and as number of moves. Two-hundred-one eighth and ninth grade students were selected as subjects for this study.

A11 subjects were administered the Rosenberg's Self-Esteem Scale (S.E.), the Physical Estimation Scale (EST), the Sport Competition Anxiety Test (SCAT), and the Fear of Negative Evaluation (FNE) 'Scale. Subjects also completed a study-designed form created to produce personal data needed to determine each subjects level of geographic mobility.

The specific hypotheses tested were: (I) that high-mobile students will have significantly lower self-esteem scores than low-mobile students, (II) that high-mobile students will have significantly lower estimation scores than low-mobile students, (III) that high-mobile students will have significantly higher competitive trait anxiety scores than low-mobile students, and (IV) that high-mobile students will have significantly higher fear of negative evaluation scores than low-mobile students.

Hypotheses I and II were supported statistically for both definitions of geographic mobility. Hypothesis IV acheived statistical support only when distance moved was used to define mobility. Discriminant function analysis was conducted in an attempt to better identify salient variables related to geographic mobility. The best 
discriminator of high and low mobility groups was identified to be global self-esteem accounting for an overall classification accuracy of $71.3 \%$.

Results of this research identified global self-esteem, physical estimation, and fear of negative evaluation as the intrapersonal factors related to the geographic mobility construct. It was recommended that future studies concentrate on distance of moves as a method of defining mobility and that they explore the possible effects of high-mobility on athletic participation and performance. 


\section{ACKNOWLEDGEMENTS}

The author extends his sincere appreciation and gratitude to $\mathrm{Dr}$. Robert J. Sonstroem who provided the expertise and guidance needed to complete this study. Also, sincere thanks are extended to the other members of the thesis committee, Dr. Arthur Sherman and Dr. Richard S. Nelson for their valuable recommendations and suggestions. The author would also like to express his appreciation to William P. LaFleur, Kathleen M. Ward and Lorraine E. White for their assistance in the administration of tests and selection of subjects.

Finally, the author wishes to thank the members of his family for the love, cooperation, and patience exhibited throughout the course of this study. 
ACKNOWLEDGEMENTS .............................. iv

TABLE OF CONTENTS ............................... v

LIST OF TABLES................................. vii

I. INTRODUCTION................................ 1

Statement of the Problem........................ 2

Significance of the Study....................... 3

Limitations of the Study....................... 4

Definition of Terms........................... 6

II. REVIEW OF LITERATURE.......................... 8

The Effect of Geographic Mobility

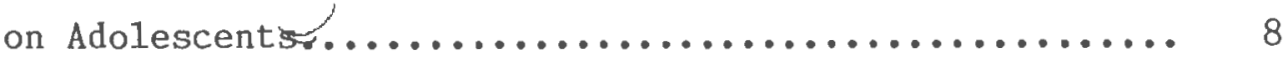

Selected Self-Esteem Measures..................... 10

Selected Situation Specific Anxiety Measures........... 13

III. PROCEDURE.................................... 19

Selection of Subjects........................... 19

Administration of Tests........................ 20

Instruments Employed......................... 20

Statistical Analysis of Data.................... 27

IV. RESULTS AND CONCLUSIONS........................ 28

Descriptive Statistics.......................... 28

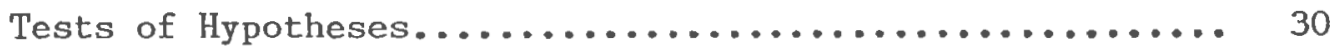

Additional Analyses........................... 43

Discussion................................ 46

Practical Implications....................... 50 
Recommendations for Future Research............... 50 BIBLIOGRAPHY................................... 52

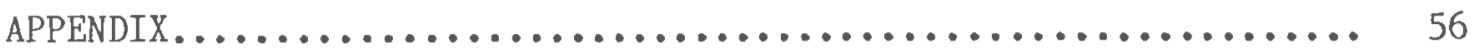

A. Attitude Questionnaire (S.E.).................. 56

B. Attitude Questionnaire (EST)................. 57

C. Illinois Competition Questionnaire (SCAT)......... 59

D. General Feelings Questionnaire (FNE).............. 61

E. Geographic Regions Defined.................... 63

F. Distance of Moves Calculations................... 64

G Student Informed Consent Form................. 65

H. Parental Informed Consent Form.................. 66 
I-1 Table of Migration Patterns.................... 5

I.I. -1 Personal Data Sheet.......................... 23

III-2 Distance of Moves........................... 25

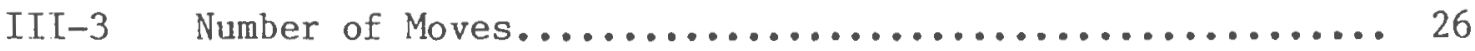

IV-1 Comparison of Grand Means to Normative Means.......... 29

IV-2 Analysis of Statistics Between Schools............... 29

IV-3 Self-Esteem of High and Low Mobility Groups

Distance Mobility Measure by Sex................ 31

IV-4 ANOVA for Self-Esteem as the Dependent Variable

Sex and Distance Moved as the Independent Variables.... 31

IV-5 Self-Esteem of High and Low Mobility Groups

Number of Moves Measure by Sex.................. 32

IV-6 ANOVA for Self-Esteem as the Dependent Variables

Sex and Number of Moves as the Independent Variables... 33

IV-7 Physical Estimation of High and Low Mobility Groups

Distance Mobility Measure by Sex................. 34

IV-8 ANOVA for Estimation as the Dependent Variable

Sex and Distance Moved as the Independent Variables.... 34

IV-9 Physical Estimation of High and Low Mobility Groups

Number of Moves Measure by Sex................... 35

IV-10 ANOVA for Estimation as the Dependent Variable

Sex and Number of Moves as the Independent Variables... 36

IV-11 Competitive Trait Anxiety of High and Low Mobility Groups

Distance Mobility Measure by Sex................ 37 
IV-12 ANOVA for Competitive Trait Anxiety

as the Dependent Variable

Sex and Distance Moved as the Independent Variables....

IV-13 Competitive Trait Anxiety of High and Low Mobility Groups

Number of Moves Measure by Sex.

IV-14 ANOVA for Competitive Trait Anxiety

as the Dependent Variable

Sex and Number of Moves as the Independent Variables...

IV-15 Fear of Negative Evaluation of High and Low

Mobility Groups

Distance Mobility Measure by Sex................... 40

IV-16 ANOVA for Fear of Negative Evaluation

as the Dependent Variable

Sex and Distance Moved as the Independent Variables.... 41

IV-17 Fear of Negative Evaluation of High and Low

Mobility Groups

Number of Moves Measure by Sex................... 42

IV-18 ANOVA for Fear of Negative Evaluation

as the Dependent Variable

Sex and Number of Moves as the Independent Variables... 42

IV-19 Correlation Matrix of Dependent Variables............ 43

IV-20 Variable Selected by Discriminant Function............ 44

IV-21 Classification by Discriminant Function Analysis....... 45

IV-22 Predictive Values for Distance Moved and Number of Moves. 46

IV-23 Pearson r Correlation Between Dependent Variables....... 48 
CHAPTER I

INTRODUCTION

This study was created when the investigator observed that junior high school students from geographically mobile families tend to lack confidence in an athletic setting, do not perform well athletically under stress, elect not to participate, and often drop from those activities they do begin. The purpose of this study was to better identify psychological variables, particularly sport specific psychological variables, which are associated with geographic mobility.

The effect of geographic mobility on children is still a topic of speculation among parents and educators. Researchers have virtually ignored the effects of the moving experience on children (Lacey and Blane, 1979). Theorists such as Mead (1934) and Erickson (1950) maintain that continuity of environment is vital to a healthy self-concept development. A study by Kroger (1980) revealed a significant negative correlation between distance of moves and self-concept scores.

Since the beginning of American history, geographic mobility has been a characteristic of this nation's population. Kroger (1980) indicates that a large percentage of adolescents will have experienced at least one residential change by the time they enter eleventh grade. Being aware of the social and academic upheaval that geographic mobility presents may enable teachers and parents of mobile children to provide additional support thereby easing the strain of adjusting to a new environment. The present study sought to expand awareness of the effect of geographic mobility on adolescents. 
Statement of the Problem

The purpose of this study was to examine the effect of geographic mobility on specified psychological variables in eighth and ninth grade students. A personal data sheet was used to define geographic mobility as both total distance moved and number of moves since grade $K$. Dependent variables were global self-esteem, estimation (self-perceptions of physical ability), competitive trait anxiety, and fear of negative evaluation. Tests were administered to two hundred and one students attending Fitch Junior High School and Cutler Junior High School in Groton, Connecticut. The sample selected from Fitch Junior High School ( $N=98$ ) was from an intact group. The Cutler Junior High School sample $(N=103)$ was selected systematically.

The specific hypotheses examined in this study were:

\section{Hypothesis I}

High-mobile students will have significantly lower self-esteem scores than low-mobile students.

Hypothesis II

High-mobile students will have significantly lower estimation scores than low-mobile students.

Hypothesis III

High-mobile students will have significantly higher competitive trait anxiety scores than low-mobile students.

Hypothesis IV

High-mobile students will have significantly higher fear of negative evaluation scores than low-mobile students.

These hypotheses were tested once for each of the two mobility 
measures. Scores were trichotomized with high-mobility group scores being compared to low-mobility group scores. Additionally, relationships between dependent variables were examined. Discriminant function analysis was conducted in an attempt to better identify salient variables related to geographic mobility.

\section{Significance of the Study}

A review of literature indicates a dire need for valid research on the effect of geographic mobility on children and adolescents. Theorists generally agree that a change of residence can have an adverse effect on the psychological development of our youth. However, very little support has been generated in laboratory settings. This study intended to enlarge the body of knowledge currently in existence.

An investigation was conducted by Kroger (1980) demonstrating that for a group of adolescents, the greater the total distance moved, the lower the self-concept score. The present study attempted to replicate this research by utilizing a global self-esteem measure and a sport specific self-esteem measure. Two situation-specific anxiety tests were selected for use in this study when a review of research indicated a relationship between the constructs of self-esteem and anxiety. If increased mobility results in low self-esteem, then the high-mobile youth should exhibit characteristics of high anxiety.

Results from this study will help to promote a better understanding of the effects of geographic mobility by publishing information in professional journals and local newspapers. Institutions that are directly involved with transient families (i.e., military bases, moving 
companies, public schools) may be of assistance by being provided with information for distribution to families directly effected by long distance moves. Additionally, a report of this study's findings will be given to the superintendent and principals of the schools involved in the study.

It is possible that the geographic mobility variable holds some importance to those in the fields of exercise science and sports psychology. Physical activity is commonly believed to influence self-esteem in a positive manner (Sonstroem, 1982) and Landers (1978) has demonstrated that elevation in anxiety levels leads to a deterioration in sports performance. If the geographic mobility variable can be shown to cause this type of psychological disturbance in children, existing reduction techniques such as exercise, biofeedback, or relaxation training can be used to reduce its effect.

In sum, knowledge gained from this study could help parents, teachers, and coaches become more aware of the problems associated with geographic mobility. Hopefully, this study will stimulate replication of this research and promote further exploration of the psychological variables that are influenced by geographic mobility.

\section{Limitations of the Study}

This study was limited by the type of subject found in the setting for this study, Groton, Connecticut. The town of Groton maintains one high school, three junior high schools, and twelve elementary schools. Considered a federally impacted area, Groton is the home of the largest submarine base in the world (Groton Directory, 1977-78). As of October 
1, 1983, $42 \%$ of the total school enrollment were considered federally connected (Groton Public Schools, 1985). The sample for this study was selected from two of the towns three junior high schools. Fitch Junior High School services most of the transient military population, whereas, Cutler Junior High School is responsible for those students who reside in middle class inland neighborhoods and upper class coastal areas.

The Table of Migration Patterns (Table I-1) compares national norms (U.S. Census, 1982) to those of the areas serving each of the three junior high schools in Groton, Connecticut (Decennial Census, 1980). These figures were based upon residential histories of the population from 1975 to 1980. The migratory rate of residents living in the Fitch Junior High School area is three times the national average, whereas,

Table I-1

Table of Migration Patterns

\begin{tabular}{|c|c|c|c|c|c|}
\hline $\begin{array}{l}\text { Residential } \\
\text { History }\end{array}$ & $\begin{array}{l}\text { National } \\
\text { Percentage }\end{array}$ & $\begin{array}{l}\text { Fitch } \\
\text { Reg }\end{array}$ & inior & $\begin{array}{r}\text { Cutler } \\
\text { Reg }\end{array}$ & inior \\
\hline$(1975-80)$ & $\%$ & $\#$ & $\%$ & \# & $\%$ \\
\hline $\begin{array}{l}\text { Total persons five } \\
\text { years and older }\end{array}$ & 100.0 & 17,434 & 100.0 & 10,857 & 100.0 \\
\hline $\begin{array}{l}\text { Nonmobile } \\
\text { (same house) }\end{array}$ & 53.0 & 3,556 & 20.4 & 6,768 & 62.3 \\
\hline $\begin{array}{l}\text { Locally Mobile } \\
\text { (same county) }\end{array}$ & 25.8 & 3,048 & 17.5 & 1,969 & 18.1 \\
\hline $\begin{array}{l}\text { Migratory } \\
\text { (different county) }\end{array}$ & 19.3 & 10,358 & 59.4 & 1,998 & 18.4 \\
\hline Same State & 10.2 & 449 & 2.6 & 445 & 4.1 \\
\hline Different State & 9.1 & 9,909 & 56.8 & 1,553 & 14.3 \\
\hline
\end{tabular}


the migratory rate of those persons residing in the Cutler Junior High School area is slightly below the national norm. The nature of this study necessitated the use of this type of sample in order to obtain an adequate number of subjects who displayed highly mobile histories. Therefore, the selected Fitch Junior High School subsample is not representative of American eighth and ninth grade students.

This study assumed that the instruments employed accurately measured global self-esteem, physical estimation, competitive trait anxiety, fear of negative evaluation, distance of moves, and number of moves. Several students were absent on the day of testing and $10.9 \%$ of the subjects selected failed to return parental permission forms. The majority of those students who failed to return the parental permission forms were negligent or apathetic. Only two students reported that their parents would not sign the form because they felt it might be detrimental to their child.

\section{Definition of Terms}

Self-Esteem/Self-Concept - "The term self-concept shall be assigned to conceptions of the self involving perceptual organization or structure. The term self-esteem shall be used when an evaluative dimension of the self is either specified or implied" (Sonstroem, 1982, p. 125).

Physical Estimation - "... self-perceptions of physical ability and sports skills" (Sonstroem, 1978, p. 98).

Fear of Negative Evaluation - An "apprehension about others' 
evaluations, distress over their negative evaluations, avoidance of evaluative situations, and the expectation that others would evaluate oneself negatively" (Watson and Friend, 1969, p. 449).

Competitive Trait Anxiety - A "tendency to perceive competitive situations as threatening and to respond to these situations with feelings of apprehension and tension" (Martens, 1977, p. 24).

$\underline{\text { Trait }} \underline{\text { Anxiety }}$ (A-Trait) - A "motive or acquired behavioral disposition that predisposes an individual to perceive a wide range of objectively nondangerous circumstances as threatening, and to respond to these with state anxiety reactions disproportionate in intensity to the magnitude of the objective danger" (Spielberger, 1966, p. 17).

$\underline{\text { State }}$ Anxiety (A-State) - An existing emotional state characterized by "subjective consciously perceived feelings of apprehension and tension, accompanied by or associated with activation or arousal of the autonomic nervous system" (Spielberger, 1966, p. 17).

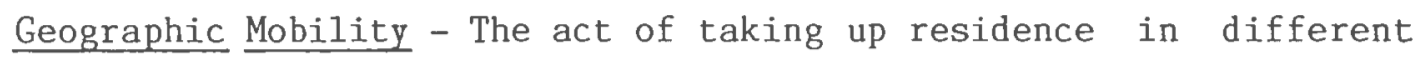
geographic areas. For the purposes of this study, geographic mobility has been measured as number of moves and distance moved. This term is used interchangeably with the following terms: residential mobility, migration, transience, and mobility. 


\section{CHAPTER II}

\section{REVIEW OF LITERATURE}

This chapter includes a review of the literature in the following areas: The Effect of Geographic Mobility on Adolescents; Selected Self-Esteem Measures; Selected Situation-Specific Trait Anxiety Measures; and a Summary.

The Effect of Geographic Mobility on Adolescents

Past research has shown geographic mobility to be related to a variety of psychological characteristics. Benson, Haycraft, Steyaert, \& Weigel (1979) found that students who change residences two or more times indicated increased difficulties in relating to peers compared to those children who moved fewer times. This study also found mobility to have negative effects on a child's achievement in the classroom. Pope, Ionescu-Pioggia, \& Yurgelun-Todd (1983) obtained a positive correlation between migration and manic-depressive illnesses. Kroger (1980) found a significant relationship between self-concept and distance of moves. However, with geographic mobility defined as "number of moves", relationships to general anxiety, test anxiety (Day, 1964) and self-concept (Kroger, 1980) were not significant. Inbar (1976) describes the importance of moving as having two major components: frequency and geo-cultural magnitude. Frequency is measured simply by the number of times an individual has moved. Geo-cultural magnitude takes into account the theory that a youth experiencing a long distance move would be less likely to encounter a similar social environment than the short distance mover or non-mobile youth. Inbar (1976) indicates that geo-cultural 
magnitude is a better measure of geographic mobility relative to psychological variables.

The age of the individual seems to be of some importance. Adults who have more control over their lives seem to be less affected by mobility, whereas, children, who typically are involuntary participants in family moves, run the greatest risk of adverse effects to a change in environment (Holland, Kaplan, \& David, 1974). Residential stability in the formative years would appear to increase the likelihood of continuity in one's social environment thereby facilitating the development of a well defined concept of self (Kroger, 1980).

Certain developmental ages are particularly susceptible to the crisis of moving. Inbar (1976) has found evidence which indicates that children in the six to eleven year age range may be most vulnerable to a change in their environment. This may be based upon social and cognitive developmental factors and it may interfere with the socialization process of developing childhood friendships. Rubin (1980) believes that the late childhood period may be most difficult since cliques are well established and difficult to penetrate at this time.

Much of the theory behind the dilemma of geographic mobility indicates that most of ten there are severe psychological consequences for the mobile child. Bowlby (1980) states that moving for young children parallels the experience of death and grief. The response is characterized by hurt, anger, sadness, and aloof detachment. Switzer (1961) believes that the core psyche difficulty for moving children is a relative feeling of loss, lessened parental attention, helplessness and fear of the unknown. Kliman (1968) compares the psychological impact of 
moving to that of feeling abandoned by a loved one. In sum, a review of literature regarding geographic mobility indicates a need for relevant research and replication.

\section{Selected Self-Esteem Measures}

This section will discuss the theory behind Rosenberg's Self-Esteem Scale (1965) and Sonstroem's Physical Estimation Scale (1978). In addition, justification for the selection of the psychological variable of self-esteem will be presented.

Social science research has given some consideration to studying the relationship between geographic mobility and mental illness or school achievement; however, relationships between geographic mobility and some of the more basic personality factors has generated little interest (Kroger, 1980). According to several psychosocial theorists, the development of the self would be influenced greatly by geographic mobility. Mead (1934) depicts the self as a social structure, developed through the interaction of the individual and his social environment. The self is defined according to how one sees others responding to it. Erikson (1950) claims that ego identity formation evolves through a process of integrating and synthesizing past childhood identifications into a coherent and unique whole. He stresses continuity within one's social environment as being important to the growing ego. The stability of one's residential environment would therefore increase the likelihood of continuity in one's social environment thus allowing for the development of a well defined self-concept.

Positive self-esteem has been long favored by mental health 
theorists and clinicians as being the essential element for a favorable ad justment to life (Coopersmith, 1967; Gergen, 1971; Horney, 1950; Rosenberg, 1963, 1979). Rosenberg (1979) defines self-concept as "the totality of the individuals thoughts and feelings having reference to himself as an object" (p. 7). This self-concept construct is divided into three broad regions; how the individual sees himself, how he would like to see himself, and how he shows himself to others. Self-esteem refers to the evaluative component of the self-concept. Wylie (1974) points out that probably more research has been devoted to self-esteem than to all other components of the self-concept combined. High self-esteem, as measured by Rosenberg's Self-Esteem Scale (1965), expresses the feeling that the individual is a person of worth; that he respects himself for what he is, but he does not necessarily feel he is superior to others. Low self-esteem refers to self-contempt, self-dissatisfaction, and self-rejection. The individual has little respect for the self he observes and he desires it to be otherwise.

Rosenberg's Self-Esteem Scale (1965) measures global self-esteem. The underlying assumption in using global self-esteem to predict behavior is that the individual has some single, basic concept of himself as superior or inferior, good or bad, and that this concept of self will have a significant impact on social conduct. It might be predicted that if a person feels he is basically superior, then he will tend to treat others as being inferior to himself (Gergen, 1971).

The emphasis on global self-concept and global self-esteem has produced less than satisfactory results when studying the relationships between global self-concept and behavior in specific situations. These disappointing results have caused many theorists to adopt the idea of 
multiple conceptions of self (Sonstroem, 1982).

The concept of multiple self-conceptions is not a new one (James, 1950; Mead, 1934). Generally, they are referred to as role identities and are nearly equivalent to Rosenberg's (1979) content elements of global self-concept. Coopersmith provides us with a description of the multiplicity of self and its relationship to global self-esteem:"... self-esteem may vary across different areas of experience and according1y to sex, age, and other role defining conditions. Thus it is conceivable that an individual would regard himself as very worthy as a student, moderately worthy as a tennis player, and totally unworthy as a musician. His overall appraisal of his abilities would presumably weight these areas according to their subjective importance, enabling him to arrive at a general level of self-esteem" (Coopersmith, 1967, p. 6). Rosenberg (1979) takes the position that components of the self-concept are not centrally equivalent to the concerns of the individual and are organized hierarchically. He believes that both global and specific levels of the concept of self should be studied.

Sonstroem's Physical Estimation Scale (1978) is utilized in this study as a measure of a sport-specific sub-category of self-esteem. Sonstroem (1975) has developed a Psychological Model for Physical Activity Participation utilizing Estimation and Attraction, from the Physical Estimation and Attraction Scales (Sonstroem, 1974). The Estimation scale measures attitudes toward the self as being able to perform and acquire physical and sport skills. The Attraction scale assesses attitudes toward a variety of vigorous physical activities and sports. This model was developed in an attempt to identify and understand the mechanisms of physical activity participation and the 
psychological benefits received from the activity (Sonstroem \& Kampper, 1980).

In developing construct validity for Estimation, three separate studies were employed utilizing three different standardized self-esteem tests. These tests were Rosenberg's Self-Esteem Scale (1965), the Self-Acceptance Scale of Bills' IAV (Bills, undated), and the Tennessee Self-Concept Scale (Fitts, 1965). Physical performance for these studies was measured by the Youth Fitness Test (AAHPER, 1965), the ten-item Fleishman Basic Fitness Test (Fleishman, 1964), and by an abbreviated version of the Youth Fitness Test. It was determined that estimations of physical ability are positively related to self-esteem; that self-perceptions of physical ability are positively related to measured physical performance; and that physical ability is not related to global self-esteem.

Other studies have helped to validate the physical estimation construct as representing a sub-category of self-esteem. Sonstroem (1976) has shown that positive self-perceptions of physical ability are related to emotional adjustment in adolescent boys and Morgan (1977) has found that Estimation is increased significantly in adult males after participation in a twenty-week exercise program.

Selected Situation-Specific Anxiety Measures

This section will discuss the theory behind situation-specific trait anxiety as measured by the Sport Competition Anxiety Test (Martens, 1977) and the Fear of Negative Evaluation Scale (Watson \& Friend, 1969). In addition, the relationship between self-esteem and 
anxiety will be explored.

As mentioned in the previous section, geographic mobility may distort the level of one's self-esteem. If this is true, then, based upon information presented in this section, geographic mobility may affect one's level of anxiety.

The relationship between self-esteem and anxiety has been confirmed but it is not clearly understood if low self-esteem increases anxiety or if increased anxiety results in low self-esteem. Horney (1950) believes anxiety tends to create low self-esteem. As the child lives through the variety of adverse circumstances within the family, he develops a basic fear, a fundamental anxiety. In order to cope, he retreats into a world of imagination where he develops an idealized image giving him strength and confidence. The image is so flattering that when the subject compares it with his real self, this latter self is so inferior by comparison, he feels contempt and hatred for it.

Rosenberg (1963) presents data supporting the theory that low self-esteem promotes anxiety. If an individual has unstable opinions, attitudes, and perceptions of himself, then he is deprived of a most valuable frame of reference. This deprivation will almost certainly provoke anxiety. Rosenberg lists four factors associated with self-esteem that might be expected to contribute to anxiety. These four factors are: instability of self-image, the presenting self, threats to self-esteem, and feelings of isolation.

Several authors have obtained associations between self-concept and self-reported trait anxiety (Wylie, 1974). Fitts (1972) discovered that patients with low self-esteem, high variability, and high maladjustment 
tend to have increased anxiety. Rosenberg (1963) reports a very strong relationship between his Self-Esteem Scale and anxiety indexed by reported secondary physiological symptoms. O'Brian \& Epstein (1974), in studying a group of undergraduate college students, found that negative changes in self-esteem produced increases in anxiety.

The situation-specific concept discussed in the previous section has been utilized in developing several anxiety scales (ie., Audience Anxiety Scale, Fear of Negative Evaluation Scale, Social Avoidance and Distress Scale, a scale for assessing the fear of snakes, heights, and darkness (Bernardo, 1979)). Mandler \& Sarason (1952) present a viewpoint that advocates moving away from investigating anxiety as a singular or global phenomenon. In studying test anxiety in academic situations, they demonstrated that the ability to predict behavior increases when the individuals' situation-specific anxiety proneness is known. "In general, situation-specific trait anxiety measures are better predictors of elevations in A-state for a particular class of stress situations than are general A-trait measures" (Spielberger, 1972, p. 490).

The Sport Competition Anxiety Test (SCAT) developed by Martens (1977) measures competitive trait anxiety which is a situation-specific trait anxiety measure. Martens (1977) has defined competitive trait anxiety as "a tendency to perceive competitive situations as threatening and to respond to these situations with feelings of apprehension and tension" (p. 24). The Sport Competition Anxiety Test (SCAT) was developed to assess this personality disposition with threat being defined as the elevation in state anxiety levels.

It was postulated by Martens (1977) that individual differences in 
competitive trait anxiety are determined by the accumulation of consequences of participation in a competitive setting. Individuals who display high competitive trait anxiety probably have received negative evaluations, have not experienced success in past competitive events, and, therefore, go into a competitive situation with expectations of failing to meet the expected requirements. It is felt that the opposite would be true of someone who exhibits low competitive trait anxiety (Martens, 1977).

In order to better determine which would better predict pre-competitive state anxiety, Martens \& Simon (1976) compared the Sport Competition Anxiety Test to two other competitive trait anxiety measures. The two other measures being compared to the SCAT were the Spielberger Trait Anxiety Inventory (Spielberger, 1970), and the coaches' rating of competitive trait anxiety. All three ratings were obtained to compare and determine how well each rating predicted the individuals self-reported pre-competitive state anxiety in competitive and non-competitive situations. Of the three scales, the SCAT correlated highest with the players level of state anxiety. Spielberger's Trait Anxiety Scale was the next best predictor with the coaches rating being the least able to predict pre-competitive state anxiety. This supports the notion that situation-specific anxiety measures are better predictors of state anxiety in competitive situations than general anxiety measures or a coaches subjective evaluation.

The Fear of Negative Evaluation Scale is a situation-specific anxiety scale which purports to measure fear of negative evaluation which is defined as "apprehension about others' evaluations, distress over their negative evaluations, avoidance of evaluative situations, and 
the expectation that others would evaluate oneself negatively" (Watson \& Friend, 1969, p. 449).

In their initial study to test the construct validity of the Fear of Negative Evaluation Scale, Watson \& Friend (1969) demonstrated that high Fear of Negative Evaluation subjects were more likely to expect disapproval from a leader than those subjects with low Fear of Negative Evaluation. High Fear of Negative Evaluation subjects were also reported to become more nervous in evaluative situations. The competitive athletic environment is, without question, a social evaluative situation. "The competitive process is an evaluative situation and most research concerned with the antecedents of state anxiety have found evaluative situations to be threatening" (Martens, 1977, p. 30). Fear of Negative Evaluation is recognized to be operative in any socio-evaluative situation (Watson \& Friend, 1969).

\section{Summary}

This review of literature indicates a need for relevant research pertaining to the social phenomenon of geographic mobility. However, because the detrimental effects 'of geographic mobility are subtle, easily overlooked, and somewhat restricted to a small population, many researchers have failed to see the importance of understanding this variable.

Self-esteem is an appropriate psychological variable for use in studying geographic mobility based on theory in literature and past research in field settings. Global self-esteem has been shown to be related to geographic mobility. The literature states a need for 
research using tests that are situation-specific as this type of test tends to be a better predictor of behavior in that particular situation.

Several theorists have noted the relationship between self-esteem and anxiety. It seems likely that if increased mobility lowers self-esteem, then increased mobility will also increase anxiety. 
Chapter III

PROCEDURE

This chapter is divided into four sections as follows: Selection of Subjects; Administration of Tests; Instruments Employed; and Statistical Analysis of Data.

\section{SELECTION OF SUBJECTS}

The purpose of this study was to examine the effect of geographic mobility on specified psychological variables in eighth and ninth grade students. Ease of administration and minimum interference with daily school routine were prime concerns in selecting subjects to be tested in this study. The investigator is a physical education instructor at Fitch Junior High School in Groton, Connecticut. There are three physical education instructors at Fitch Junior High School and students are assigned to physical education classes at random by the guidance department. The Fitch Junior High School sample was selected by taking a11 students assigned to the investigator's class roster $(\mathrm{N}=119) .98$ subjects agreed to participate and complete all tests. Nine failed to return parental permission slips, eleven were absent from school when the test was administered, and one subject failed to complete the test proper1y.

Every third student on the eighth and ninth grade alphabetized class roster at Cutler Junior High School in Groton, Connecticut was selected $(N=138) .103$ students agreed to participate and complete all tests. Nineteen students failed to return parental permission slips while sixteen were absent from school when the test was administered. 


\section{ADMINISTRATION OF TESTS}

Approval from the schools' principals was required in order to administer the questionnaires. Mr. Donald Scott and Mr. George Sneider, principals at Fitch Junior High School and Cutler Junior High School respectively, gave their consent for the testing to take place. Parental consent was also required before the subjects could be tested. Consent Forms were sent home with the subjects two weeks prior to testing.

Fitch Junior High School students were tested in vacant classrooms during their scheduled physical education period. The questionnaires were administered to the entire sample selected from Cutler Junior High School in the school cafeteria during the first thirty minutes of the school day. Before the subjects were allowed to complete the questionnaires, they were asked to sign an informed consent form. They were told that they were part of a survey testing adolescent attitudes about themselves and about physical activity. The students were assured of personal privacy and that completion of the test was not required.

\section{INSTRUMENTS EMPLOYED}

\section{Rosenberg Self-Esteem Scale}

This scale was used to test global self-esteem. According to Hellison (1970) this instrument possesses the advantages of ease of administration and scoring, economy of time, several measures of validity, and high reproducibility and scalability coefficients. Rosenberg (1965) cites a study by Silbert and Tippett reporting a 
test-retest reliability of .85 for this instrument.

The scale is a ten item test that has the respondent answer whether he/she strongly agrees, agrees, disagrees, or strongly disagrees with self-esteem questions. The test was scored using a Likert scale with a range of 10 to 40 . A score of 10 indicates low self-esteem while a score of 40 is indicative of high self-esteem (see Appendix A).

Physical Estimation Scale (EST)

This scale measures self-perceptions of physical ability. The rationale for the development of this instrument implies that physical estimation represents a sub-category of global self-esteem. This scale has demonstrated a Kuder-Richardson 20 reliability coefficient of .87 and a one-week stability coefficient of .92. Evidence of validity is shown with construct validity coefficients of .43 and .51 (Sonstroem, 1978).

The 33 items contained in this scale employ slightly different self-perception stimulus catregories. Items refer to possession of strength compared to peers, possession of physical fitness compared to peers, possession of specific skills, or potential to acquire a.specific skill. The scale contains 20 positively phrased statements and 13 negatively phrased statements. Scores range from 0 to 33 with higher scores being indicative of more favorable self-perceptions of physical ability. (see Appendix B).

Sport Competition Anxiety Test (SCAT)

This test was developed by Martens (1977) to assess competitive trait anxiety in an individual. This instrument has demonstrated 
internal consistency, content validity and concurrent validity. A test-retest reliability coefficient of .77 has been acheived and Kuder-Richardson 20 reliability scores of .97 and .95 have been shown (Martens, 1977).

Presented as the Illinois Competition Questionnaire, this inventory contains fifteen statements about how the individual usually feels when competing in sports and games. Only ten of the fifteen items are scored. Five spurious items are added in order to lower response bias toward the scored items. The response options are "hardly ever", "sometimes", and "often". The SCAT has a range of scores from 10 (low competitive trait anxiety) to 30 (high competitive trait anxiety).

\section{Fear of Negative Evaluation Scale (FNE)}

This scale measures social-evaluative anxiety. It has demonstrated test-retest correlations of .78 and .94 and Kuder-Richardson 20 reliability scores of .94 and .96 have been achieved. The mean biserial correlation of each item with its own scale was .72. Watson and Friend (1969) present five experimental studies that provide validation of this scale.

This instrument consists of thirty true-false items with seventeen of the thirty items being true while the remaining thirteen are false. Scores range from 0 to 30 with higher scores indicating high Fear of Negative Evaluation (see Appendix D).

Personal Data Sheet (Table III-1)

This instrument was developed by the investigator to obtain personal information relevant to this study (distance moved, number of 
Table III-1

Personal Data Sheet

Name

(circle one) male female

List in the sections provided the town and state you lived in while attending school at each grade level. If you lived in more than one town during any school year, write down each town and state lived in.

Grade K

Grade 1

Grade 2

Grade 3

Grade 4

Grade 5

Grade 6

Grade 7

Grade 8

Grade 9 
moves, sex). The validity of this instrument was tested by administering it to 19 seventh grade students at Fitch Junior High School in Groton, Connecticut. Information obtained from the personal data sheets was verified with personal interviews with the respondents and by comparing the sheets to school records. A11 but one of the students completed the form properly. The student who did not complete the form properly could not remember where she lived while attending kindergarten and first grade.

Students were instructed to list in the sections provided on the Persona1 Data Sheet (Table III-1) the town and state they lived in while attending school at each grade level. If the student had lived in more than one town or state during the school year, then he would write down each town and state lived in on the appropriate line. The distance of each move was given a value based on the scale used by Kroger (1980) which appears in Appendix F. For each student, the total distance moved was calculated by totaling the values given to all moves. Number of moves was determined by counting the number of times the student had changed residences.

Distance of move data are presented in Table III-2. Distance of moves codes ranged from 0 to 39, with a mode of 0 and a median of 4 . Subjects having a distance code of 0 comprised the largest group (34.3\%), followed by $10.9 \%$ with distance codes of 2 , and $7.0 \%$ with distance codes of 6 . Distance codes were trichotomized with the lower third group scores $(\mathrm{N}=69)$ being compared to the upper third group scores $(N=67)$.

Number of moves data are presented in Table III-3. The number of 
Table III-2

Distance of Moves

\begin{tabular}{|c|c|c|}
\hline Variable & $\begin{array}{c}(201) \\
\mathrm{N}\end{array}$ & $\begin{array}{c}\text { Percent } \\
(100)\end{array}$ \\
\hline \multicolumn{3}{|c|}{ Distance of Moves Code* } \\
\hline 0 & 69 & 34.3 \\
\hline 2 & 22 & 10.9 \\
\hline 3 & 3 & 1.5 \\
\hline 4 & 9 & 4.5 \\
\hline 5 & 1 & 0.5 \\
\hline 6 & 14 & 7.0 \\
\hline 7 & 2 & 1.0 \\
\hline 8 & 3 & 1.5 \\
\hline 9 & 2 & 1.0 \\
\hline 10 & 9 & 4.5 \\
\hline 12 & 11 & 5.5 \\
\hline 14 & 6 & 3.0 \\
\hline 15 & 3 & 1.5 \\
\hline 16 & 6 & 3.0 \\
\hline 17 & 1 & 0.5 \\
\hline 18 & 12 & 6.0 \\
\hline 19 & 2 & 1.0 \\
\hline 20 & 2 & 1.0 \\
\hline 21 & 3 & 1.5 \\
\hline 22 & 2 & 1.0 \\
\hline 24 & 3 & 1.5 \\
\hline 26 & 4 & 2.0 \\
\hline 27 & 1 & 0.5 \\
\hline 28 & 2 & 1.0 \\
\hline 31 & 2 & 1.0 \\
\hline 32 & 1 & 0.5 \\
\hline 33 & 1 & 0.5 \\
\hline 34 & 2 & 1.0 \\
\hline 36 & 1 & 0.5 \\
\hline 38 & 1 & 0.5 \\
\hline 39 & 1 & 0.5 \\
\hline
\end{tabular}

*Distance code was calculated for each subject by totaling the values given to a11 moves.

moves experienced by subjects ranged from 0 to 11 , with a mode of 0 and a median of 1 . The largest group of subjects (34.3\%) had moved 0 times, 
followed'by $18.4 \%$ of the subjects moving 1 time, and $18.4 \%$ moving 3 times. The number of moves variable was trichotomized with the lower third group scores $(\mathrm{N}=69)$ being compared to the upper third group scores $(N=69)$.

Students who move a great distance once, or several times within a small geographic area may not suffer the effects of geographic mobility. An attempt was made to discriminate between non-movers and subjects who were most likely to experience psychological change as a result of a

Table III-3

Number of Moves

Variable

(201)

$\mathrm{N}$

Percent

(100)

Number of Moves

0

1

2

3

4

5

6

7

8

9

11
69

37

26

37

10

8

5

5

1

2

1
34.3

18.4

12.9

18.4

5.0

4.0

2.5

2.5

0.5

1.0

0.5 
high rate of mobility by eliminating the middle third group of subjects. Subjects were classified once based on their distance of moves code and again based on the number of times moved. For both distance of moves and number of moves, the low-mobile group consisted of all subjects who were non-mobile. For distance of moves, the high-mobile group consisted of subjects who had distance of moves codes that ranged from 12-39. For number of moves, the high-mobile group consisted of subjects who had moved three or more times.

\section{STATISTICAL ANALYSIS OF DATA}

I.B.M. cards for all data collected in the study were punched and processed at the Academic Computer Center at the University of Rhode Island. Hypotheses I, II, III, and IV were tested once for each of the two mobility measures by a two factor analysis of variance in which the independent factors were mobility and sex. Scores were trichotomized with the upper third group (high-mobile) scores being compared to the lower third group (low-mobile) scores. Additionally, relationships between dependent variables were examined. Discriminant function analysis was used to identify salient variables related to geographic mobility . 


\section{CHAPTER IV}

\section{RESULTS AND CONCLUSIONS}

This chapter is divided into six sections as follows: Descriptive Statistics; Tests of Hypotheses; Additional Analyses; Discussion; Practical Implications; and Recommendations for Future Research.

\section{DESCRIPTIVE STATISTICS}

Means for Rosenberg's Self-Esteem Scale(S.E.), Sonstroem's Physical Estimation Scale(EST), Martens' Sport Competition Anxiety Test(SCAT), and Watson and Friend's Fear of Negative Evaluation Scale(FNE) are shown in Table IV-1.

A mean score of 30.76 was obtained using Rosenberg's Self-Esteem Scale. Comparative means could not be determined as studies using this scale either fail to report established means or use Guttman scaling to score the test rather than the Likert scale utilized in this study. An EST mean of 20.64 was slightly higher than a mean of 19.59 which was reported by Sonstroem and Kampper (1980) for middle school boys. The present study tested junior high school girls and boys. Normative EST means for junior high school girls could not be determined. A SCAT mean of 21.94 was obtained. This is higher than the normative mean presented by Martens (1977) of 20.60. This difference may be the result of the use of college age adults by Martens (1977) and his use of a sample consisting of a high percentage of male subjects $(\%=70.1)$. The FNE values obtained were comparable to the norm values of Watson and Friend (1969). The mean raw score obtained in this study was 15.28, whereas, the normative mean for University of Toronto undergraduates was 
determined to be 15.47 .

Table IV-1

Comparison of Grand Means to Normative Means

\begin{tabular}{ccccc}
\hline & S.E. & EST & SCAT & FNE \\
\hline $\begin{array}{c}\text { Grand Means } \\
(\mathrm{N})\end{array}$ & $\begin{array}{c}30.76 \\
(201)\end{array}$ & $\begin{array}{c}20.64 \\
(201)\end{array}$ & $\begin{array}{c}21.94 \\
(201)\end{array}$ & $\begin{array}{l}15.28 \\
(201)\end{array}$ \\
$\begin{array}{c}\text { Normative Means } \\
(\mathrm{N})\end{array}$ & 19.59 & 20.60 & 15.47 \\
& $(393)$ & $(528)$ & $(205)$ \\
\hline
\end{tabular}

Table IV-2 presents data comparing the mean scores of Self-Esteem(S.E.), EST, SCAT, and FNE between subjects selected from Fitch Junior High School and Cutler Junior High School. When a test for significant differences was conducted, a $t$ ratio of 2.57 was obtained for the self-esteen variable. This was significant at the .01 level. T ratios of $1.55,0.33$, and 0.54 were obtained for the respective variables EST, SCAT, and FNE. At the .05 level of significance, a $t$ ratio of 1.96 is required. Therefore, it was concluded that subjects at

Table IV-2

Analysis of Statistics Between Schools

\begin{tabular}{|c|c|c|c|c|c|}
\hline Schools & $N$ & S.E. & EST & SCAT & FNE \\
\hline Cutler JHS & 103 & 31.49 & 21.30 & 22.06 & 15.54 \\
\hline Fitch JHS & 98 & 29.99 & 19.95 & 21.81 & 15.01 \\
\hline t & & 2.57 & 1.55 & 0.33 & 0.54 \\
\hline $\mathrm{p}$ & & .01 & n.s. & n.s. & n.s. \\
\hline
\end{tabular}


Cutler Junior High School had significantly higher self-esteem scores than subjects at Fitch Junior High School. It was also concluded that subjects at Cutler Junior High School did not have significantly different EST, SCAT, or FNE scores than subjects at Fitch Junior High School.

\section{TESTS OF HYPOTHESES}

Each hypothesis was tested once for each of the two mobility measures with the upper third mobility group being compared to the lower third mobility group. For the distance of moves mobility measure, low-mobile students had a distance measure of $0(N=69)$. High-mobile students were those who had a distance measure of 12 or above $(N=67)$. The table used to determine the distance of moves measure can be found in Appendix F. For the number of moves mobility measure, low-mobile students were those who had never moved $(\mathrm{N}=69)$. High-mobile students were those who had moved three or more times $(N=69)$. Therefore, in the case of both analyses, the low-mobile group was actually a non-mobile group.

All four hypotheses were tested by double classification analysis of variance with sex and movement measures as the two independent factors. Interaction effects were not tested since there were no prior reasons to expect interaction.

\section{Hypothesis I}

High-mobile students will have significantly lower self-esteem scores than low-mobile students. 
Table IV-3

Self-Esteem of High and Low Mobility Groups

(Distance Mobility Measure by Sex)

\begin{tabular}{|c|c|c|c|c|}
\hline \multirow{3}{*}{$\begin{array}{l}\text { High } \\
\text { Mobile }\end{array}$} & $T$ & Male & Female & Total \\
\hline & $(\mathrm{N})$ & (27) & (40) & $(67)$ \\
\hline & $\overline{\mathrm{X}}$ & 30.00 & 28.23 & 28.94 \\
\hline \multirow{2}{*}{$\begin{array}{l}\text { Low } \\
\text { Mobile }\end{array}$} & $(\mathrm{N})$ & (41) & (28) & $(69)$ \\
\hline & $\bar{X}$ & 32.66 & 31.25 & 32.09 \\
\hline \multirow{2}{*}{ Total } & $(\mathrm{N})$ & (68) & (68) & \\
\hline & $\bar{x}$ & 31.60 & 29.47 & \\
\hline
\end{tabular}

Table IV-3 presents means for high and low distance groups by sex. The number of subjects in each category is included above the category

\section{Table IV-4}

ANOVA for Self-Esteem as the Dependent Variable,

Sex and Distance Moved as Independent Variables

\begin{tabular}{lrrrrc}
\hline SV & df & \multicolumn{1}{c}{ SS } & MS & \multicolumn{1}{c}{ F } & p \\
\hline Distance & 1 & 336.58 & 336.58 & 23.63 & .0001 \\
Sex & 1 & 82.70 & 82.70 & 5.81 & .02
\end{tabular}


mean. The marginals of Table IV-3 indicate that the low-mobile group had higher self-esteem means $(\bar{X}=32.09)$ as compared to high-mobile students $(\bar{X}=28.94)$. Boys also showed higher self-esteem means $(\bar{X}=31.60)$ as compared to girls $(\bar{X}=29.47)$.

As stated previously, these effects were tested by means of a two-way analysis of variance. Table IV-4 presents the ANOVA results.

Table IV-5

Self-Esteem of High and Low Mobility Groups

(Number of Moves Measure by Sex)

\begin{tabular}{|c|c|c|c|c|}
\hline & 1 & Male & Female & Total \\
\hline \multirow{2}{*}{$\begin{array}{l}\text { High } \\
\text { Mobile }\end{array}$} & $(\mathrm{N})$ & (26) & (43) & (69) \\
\hline & $\overline{\mathrm{X}}$ & 30.19 & 28.81 & 29.33 \\
\hline \multirow{2}{*}{$\begin{array}{l}\text { Low } \\
\text { Mobile }\end{array}$} & $(\mathrm{N})$ & (41) & (28) & (69) \\
\hline & $\bar{X}$ & 32.66 & 31.25 & 32.09 \\
\hline \multirow{2}{*}{ Total } & $(\mathrm{N})$ & (67) & (71) & \\
\hline & $\bar{X}$ & 31.70 & 29.77 & \\
\hline
\end{tabular}

As indicated in Table IV-4 both a significant distance of moves effect $(F=23.63, p<.0001)$ and a significant sex effect were obtained $(F=5.81, p<.02)$. It was concluded that high-mobile students had significantly lower self-esteem scores than low-mobile students when distance moved was used to define mobility. It was concluded also that girls reported significantly lower self-esteem than boys. 
Table IV-5 presents means for high and low number of moves groups by sex. The number of subjects in each category is included above the category mean. The marginals of Table IV-5 reveal that the low-mobile group had higher self-esteen means $(\bar{X}=32.09)$ as compared to high-mobile students $(\bar{X}=29.33)$. Boys also showed higher self-esteem means $(\bar{X}=31.70)$ as compared to girls $(\bar{X}=29.77)$.

\section{Table IV-6}

ANOVA for Self-Esteem as the Dependent Variable,

Sex and Number of Moves as Independent Variables

\begin{tabular}{lrrrrr}
\hline SV & df & SS & MS & F & p \\
\hline Moves & 1 & 197.40 & 197.40 & 11.93 & .001 \\
Sex & 1 & 127.98 & 127.98 & 7.74 & .01 \\
Error & 135 & $2,233.03$ & 16.54 & & \\
Total & 137 & $2,558.41$ & & & \\
\hline
\end{tabular}

Two-way analysis of variance results are presented in Table IV-6.

As indicated in Table IV-6 both a significant number of moves effect $(F=11.93, p<.001)$ and a significant sex effect were obtained $(F=7.74, p<.01)$. It was concluded that high-mobile students had significantly lower self-esteem scores than low-mobile students when number of moves was used to define mobility. It was concluded also that girls reported significantly lower self-esteem than boys.

Hypothesis II

High-mobile students will have significantly lower estimation scores than low-mobile students. 
Table IV-7

Physical Estimation of High and Low Mobility Groups

(Distance Mobility Measure by Sex)

\begin{tabular}{|c|c|c|c|c|}
\hline \multirow{3}{*}{$\begin{array}{l}\text { High } \\
\text { Mobile }\end{array}$} & & Male & Female & Total \\
\hline & $(N)$ & $(27)$ & $(40)$ & $(67)$ \\
\hline & $\bar{X}$ & 21.22 & 16.13 & 18.18 \\
\hline \multirow{2}{*}{$\begin{array}{l}\text { Low } \\
\text { Mobile }\end{array}$} & $(N)$ & (41) & (28) & (69) \\
\hline & $\bar{X}$ & 23.90 & 18.86 & 21.86 \\
\hline \multirow{2}{*}{ Total } & $(\mathrm{N})$ & $(68)$ & (68) & \\
\hline & $\bar{X}$ & 22.84 & 17.25 & \\
\hline
\end{tabular}

Table IV-7 presents means for high and low distance groups by sex.

Table IV-8

ANOVA for Estimation as the Dependent Variable,

Sex and Distance Moved as Independent Variables

\begin{tabular}{lrrrrr} 
SV & df & SS & MS & F & p \\
\hline Distance & 1 & 459.33 & 459.33 & 14.73 & .0003 \\
Sex & 1 & 842.30 & 842.30 & 27.02 & .0001 \\
Error & 133 & $4,146.10$ & 31.17 & & \\
Total & 135 & $5,447.74$ & & &
\end{tabular}


The number of subjects in each category is included above the category mean. The marginals of Table IV-7 indicate that the low-mobile group had higher physical estimation means $(\bar{X}=21.86)$ as compared to high-mobile students $(\bar{X}=18.18)$. Boys also showed higher physical estimation means $(\bar{X}=22.84)$ as compared to $\operatorname{girls}(\bar{X}=17.25)$.

As stated previously; these effects were tested by means of a two-way analysis of variance. Table IV-8 presents the ANOVA results.

As indicated in Table IV-8 both a significant distance of moves effect $(F=14.73, p<.0003)$ and a significant sex effect were obtained $(F=27.02, p<.0001)$. It was concluded that high-mobile students had significantly lower physical estimation scores than low-mobile students

Table IV-9

Estimation of High and Low Mobility Groups

(Number of Moves Mobility Measure by Sex)

\begin{tabular}{|c|c|c|c|c|}
\hline \multirow{3}{*}{$\begin{array}{l}\text { High } \\
\text { Mobile }\end{array}$} & 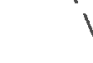 & Male & Female & Total \\
\hline & $(\mathrm{N})$ & $(26)$ & (43) & (69) \\
\hline & $\bar{X}$ & 21.81 & 16.26 & 18.35 \\
\hline \multirow{2}{*}{$\begin{array}{l}\text { Low } \\
\text { Mobile }\end{array}$} & $(\mathrm{N})$ & (41) & $(28)$ & (69) \\
\hline & $\overrightarrow{\mathrm{X}}$ & 23.90 & 18.86 & 21.86 \\
\hline \multirow{2}{*}{ Total } & $(\mathrm{N})$ & (67) & (71) & \\
\hline & $\bar{X}$ & 23.09 & 17.28 & \\
\hline
\end{tabular}


when distance moved was used to define mobility. It was concluded also that girls reported significantly lower physical estimation than boys.

Table IV-9 presents means for high and low number of moves groups by sex. The number of subjects in each category is included above the category mean. The marginals of Table IV-9 indicate that the low-mobile group had higher physical estimation means $(\overline{\mathrm{X}}=21.86)$ as compared to high-mobile students $(\bar{X}=18.35)$. Boys also showed higher physical estimation means $(\bar{X}=23.09)$ as compared to girls $(\bar{X}=17.28)$.

Two-way analysis of variance results are presented in Table IV-10.

Table IV-10

ANOVA for Estimation as the Dependent Variable, Sex and Number of Moves as Independent Variables

\begin{tabular}{lrrrrr}
\hline SV & df & \multicolumn{1}{c}{ SS } & \multicolumn{1}{c}{ MS } & \multicolumn{1}{c}{ F } & p \\
\hline Moves & 1 & 182.46 & 182.46 & 5.65 & .02 \\
Sex & 1 & $1,162.75$ & $1,162.75$ & 36.02 & .0001 \\
Error & 135 & $4,357.37$ & 32.28 & & \\
Tota1 & 137 & $5,702.58$ & & & \\
\hline
\end{tabular}

As indicated in Table IV-10 both a significant number of moves effect $(F=5.65, p<.02)$ and a significant sex effect were obtained ( $F$ $=36.02, \mathrm{p}<.0001)$. It was concluded that high-mobile students had significantly lower physical estimation scores than low-mobile students 
when number of moves was used to define mobility. It was concluded also that girls reported significantly lower physical estimation than boys.

Hypothesis III

High-mobile students will have significantly higher competitive trait anxiety scores than low-mobile students.

Table IV-11

Competitive Trait Anxiety of High and Low Mobility Groups (Distance Mobility Measure by Sex)

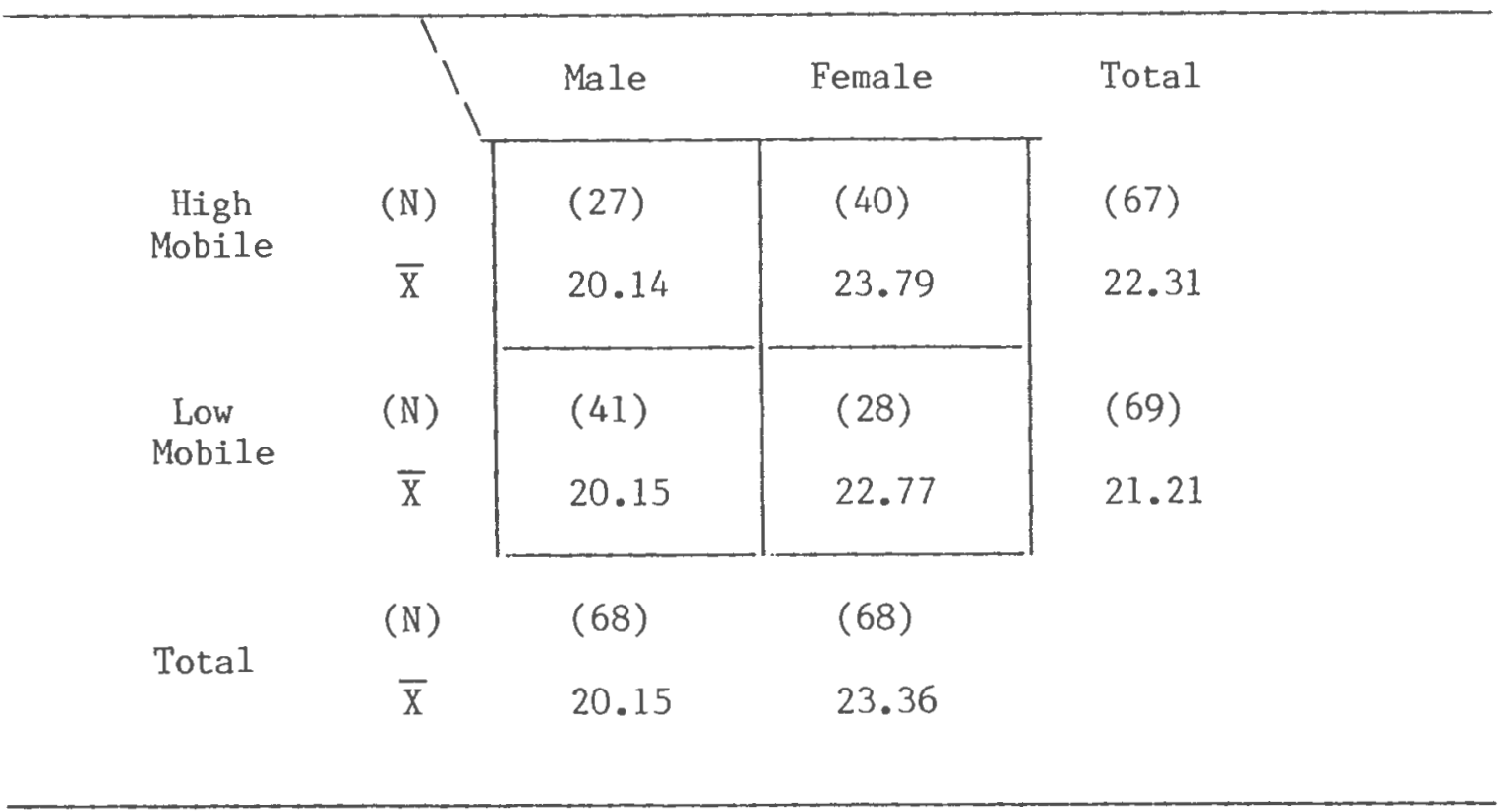

Table IV-11 presents means for high and low distance groups by sex. The number of subjects in each category is included above the category mean. The marginals of Table IV-11 indicate that the low-mobile group had lower competitive trait anxiety means $(\bar{X}=21.21)$ as compared to high-mobile students $(X=22.31)$. Boys also showed lower competitive trait anxiety means $(\bar{X}=20.15)$ as compared to girls $(\bar{X}=23.36)$. 
As stated previously, these effects were tested by means of a two-way analysis of variance. Table IV-12 presents the ANOVA results.

Table IV-12

ANOVA for Competitive Trait Anxiety as the Dependent Variable, Sex and Distance Moved as Independent Variables

\begin{tabular}{lrrrrr} 
SV & df & SS & MS & F & p \\
\hline Distance & 1 & 41.11 & 41.11 & 1.45 & $.23\left(\mathrm{n}\right.$. s. $\left.^{\prime}\right)$ \\
Sex & 1 & 319.03 & 319.03 & 11.27 & .002 \\
Error & 133 & $3,766.05$ & 28.32 & & \\
Tota1 & 135 & $4,126.18$ & &
\end{tabular}

Table IV-12 indicates that the distance of moves effect $(F=1.45, P$ $<.23($ n.s.) ) was not significant. However, a significant sex effect was obtained $(F=11.27, \mathrm{p}<.002)$. It was concluded that high-mobile students did not have significantly higher competitive trait anxiety scores than low-mobile students when distance moved was used to define mobility. It was concluded also that girls reported significantly higher competitive trait anxiety than boys.

Table IV-13 presents means for high and low number of moves groups by sex. The number of subjects in each category is included above the category mean. The marginals of Table IV-13 indicate that the low-mobile group had lower competitive trait anxiety means $(\bar{X}=21.21)$ as compared to high-mobile students $(\bar{X}=22.41)$. Boys also showed lower competitive trait anxiety means $(\bar{X}=20.04)$ as compared to girls $(\bar{X}=23.49)$. 
Table IV-13

Competitive Trait Anxiety of High and Low Mobility Groups

(Number of Moves Mobility Measure by Sex)

\begin{tabular}{|c|c|c|c|c|}
\hline & & Male & Female & Total \\
\hline \multirow{2}{*}{$\begin{array}{l}\text { High } \\
\text { Mobile }\end{array}$} & $(\mathrm{N})$ & $(26)$ & (43) & $(69)$ \\
\hline & $\bar{X}$ & 19.86 & 23.95 & 22.41 \\
\hline \multirow{2}{*}{$\begin{array}{l}\text { Low } \\
\text { Mobile }\end{array}$} & $(\mathrm{N})$ & (41) & (28) & $(69)$ \\
\hline & $\overline{\mathrm{X}}$ & 20.15 & 22.77 & 21.21 \\
\hline \multirow{2}{*}{ Total } & $(\mathrm{N})$ & $(67)$ & (71) & \\
\hline & $\overline{\mathrm{X}}$ & 20.04 & 23.49 & \\
\hline
\end{tabular}

Two-way analysis of variance results are presented in Table IV-14.

Table IV-14

ANOVA for Competitive Trait Anxiety as the Dependent Variable, Sex and Number of Moves as Independent Variables

\begin{tabular}{lrrrrr} 
SV & df & \multicolumn{1}{c}{ SS } & MS & F & p \\
\hline Moves & 1 & 7.20 & 7.20 & 0.26 & .61 (n.s.) \\
Sex & 1 & 409.96 & 409.96 & 14.58 & .0003 \\
Error & 135 & $3,795.57$ & 28.12 & & \\
Total & 137 & 4.212 .72 & &
\end{tabular}


Table IV-14 indicates that the number of moves effect $(F=0.26, p<$ .61 (n.s.)) was not significant. However, a significant sex effect was obtained $(F=14.58, p<.0003)$. It was concluded that high-mobile students did not have significantly higher competitive trait anxiety scores than low-mobile students when number of moves was used to define mobility. It was concluded also that girls reported significantly higher competitive trait anxiety than boys.

\section{Hypothesis IV}

High-mobile students will have significantly higher fear of negative evaluation scores than low-mobile students.

Table IV-15

Fear of Negative Evaluation of High and Low Mobility Groups

(Distance Mobility Measure by Sex)

\begin{tabular}{|c|c|c|c|c|}
\hline & & Male & Female & Total \\
\hline \multirow{2}{*}{$\begin{array}{l}\text { High } \\
\text { Mobile }\end{array}$} & $(\mathrm{N})$ & (27) & (40) & (67) \\
\hline & $\overline{\mathrm{X}}$ & 15.07 & 17.93 & 16.78 \\
\hline \multirow{2}{*}{$\begin{array}{l}\text { Low } \\
\text { Mobile }\end{array}$} & $(\mathrm{N})$ & (41) & (28) & (69) \\
\hline & $\overline{\mathrm{X}}$ & 13.44 & 15.93 & 14.45 \\
\hline \multirow{2}{*}{ Total } & $(\mathbb{N})$ & (68) & (68) & \\
\hline & $\vec{X}$ & 14.09 & 17.10 & \\
\hline
\end{tabular}

Table IV-15 presents means for high and low distance groups by sex. The number of subjects in each category is included above the category 
mean. The marginals of Table IV-15 indicate that the low-mobile group had lower fear of negative evaluation means $(\bar{X}=14.45)$ as compared to high-mobile students $(\bar{X}=16.78)$. Boys also showed lower fear of negative evaluation means $(\bar{X}=14.09)$ as compared to girls $(\bar{X}=17.10)$.

These effects were tested by means of a two-way analysis of variance shown in Table IV-16.

Table IV-16

ANOVA for Fear of Negative Evaluation as the Dependent Variable, Sex and Distance Moved as Independent Variables

\begin{tabular}{lrrrrr}
\hline SV & df & \multicolumn{1}{c}{ SS } & MS & F & p \\
& 1 & 184.04 & 184.04 & 4.08 & .05 \\
Distance & 1 & 233.06 & 233.06 & 5.16 & .03 \\
Sex & 133 & $6,001.65$ & 45.13 & & \\
Error & 135 & $6,418.76$ & & \\
Total & & & & \\
\hline
\end{tabular}

As indicated in Table IV-16 both a significant distance of moves effect $(F=4.09, p<.05)$ and a significant sex effect were obtained ( $F$ $=5.16, p<.03)$. It was concluded that high-mobile students had significantly greater fear of negative evaluation scores than low-mobile students when distance moved was used to define mobility. It was concluded also that girls reported significantly higher fear of negative evaluation than boys.

Table IV-17 presents means for high and low number of moves groups 
Table IV-17

Fear of Negative Evaluation of High and Low Mobility Groups (Number of Moves Mobility Measure by Sex)

\begin{tabular}{|c|c|c|c|c|}
\hline & & Male & Female & Total \\
\hline \multirow{2}{*}{$\begin{array}{l}\text { High } \\
\text { Mobile }\end{array}$} & $(N)$ & $(26)$ & (43) & (69) \\
\hline & $\bar{X}$ & 13.62 & 17.58 & 16.09 \\
\hline \multirow{2}{*}{$\begin{array}{l}\text { Low } \\
\text { Mobile }\end{array}$} & $(\mathrm{N})$ & $(41)$ & (28) & (69) \\
\hline & $\bar{X}$ & 13.44 & 15.93 & 14.45 \\
\hline \multirow{2}{*}{ Tota1 } & $(\mathrm{N})$ & $(67)$ & (71) & \\
\hline & $\bar{X}$ & 13.51 & 16.93 & \\
\hline
\end{tabular}

by sex. The number of subjects in each category is included above the category mean. The marginals of Table IV-17 indicate that the low-mobile group had lower fear of negative evaluation means $(\bar{X}=14.45)$ as

Table IV-18

ANOVA for Fear of Negative Evaluation as the Dependent Variable, Sex and Number of Moves as Independent Variables

\begin{tabular}{lrrrrr}
\hline SV & df & SS & MS & F & p \\
\hline Moves & 1 & 28.93 & 28.93 & 0.63 & $.43(\mathrm{n.s.})$ \\
Sex & 1 & 403.69 & 403.69 & 8.82 & .004 \\
Error & 135 & $6,180.47$ & 45.78 & & \\
Total & 137 & $6,613.08$ & &
\end{tabular}


compared to high-mobile students $(\bar{X}=16.09)$. Boys also showed lower fear of negative evaluation means $(\bar{X}=13.51)$ as compared to girls $(\bar{X}=$ 16.93).

Two-way analysis of variance results are presented in Table IV-18.

Table IV-18 indicates that the number of moves effect $(F=0.63, p<$ .43 (n.s.)) was not significant. However, a significant sex effect was obtained $(F=8.82, p<.004)$. It was concluded that high-mobile students did not have significantly higher fear of negative evaluation scores than low-mobile students when number of moves was used to define mobility. It was concluded also that girls reported significantly higher fear of negative evaluation than boys.

\section{ADDITIONAL ANALYSES}

Two additional purposes of this study were to examine relationships between study variables and to identify those psychological variables which best discriminated between high and low mobile groups. Table IV-19 presents a correlation matrix of study dependent variables.

\section{TABLE IV-19}

Correlation Matrix of Dependent Variables

\begin{tabular}{lllll}
\hline & S.E. & EST & SCAT & FNE \\
\hline S.E. & 1.00 & 0.51 & -0.36 & -0.46 \\
EST & - & 1.00 & -0.39 & -0.43 \\
SCAT & - & - & 1.00 & 0.47 \\
FNE & - & - & - & 1.00 \\
\hline $\mathrm{N}=201$ & & & &
\end{tabular}


High relationships were observed between all dependent variables with major associations being found arong self-esteern, estimation, and fear of negative evaluation. Relationships with the latter variable were negative.

TABLE IV-20

Variable Selected by Discriminant Function

(Distance Moved)

Variable

Selected

Self-Esteem

22.81
Probability

.0001

Canonica1 $r=0.381$

Discriminant function analysis was employed as a means of identifying the best discriminator of high and low mobility groups. These analyses employed self-esteem and estimation as predictors since they were the two significant variables identified in the analysis of variance.

Table IV-20 indicates that self-esteem was the only variable selected for the discriminant function $(F=22.81, p<.0001)$. This function produced a canonical correlation coefficient of 0.381 with group membership. Table IV-21 presents results when each member was classified on the basis of the discriminant function. Table IV-21 shows that the function correctly classified 39 of the actual 67 members of the high group. It, also, correctly classified 58 of the 69 members of the low group. This accounted for an overall classification accuracy of $71.3 \%$ (97 of 136 subjects). This represents roughly a $21 \%$ improvement 
TABLE IV-21

Classification by Discriminant Function Analysis

(Distance Moved)

\begin{tabular}{|c|c|c|c|c|}
\hline \multirow{3}{*}{$\begin{array}{l}\text { High } \\
\text { Mobile }\end{array}$} & \multirow{3}{*}{$(\mathrm{N})$} & $\begin{array}{l}\text { High } \\
\text { Mobile }\end{array}$ & $\begin{array}{l}\text { Low } \\
\text { Mobile }\end{array}$ & Total \\
\hline & & (39) & (28) & \multirow[t]{2}{*}{$(67)$} \\
\hline & & $58.2 \%$ & $41.8 \%$ & \\
\hline \multirow{4}{*}{$\begin{array}{l}\text { Low } \\
\text { Mobile }\end{array}$} & $(\mathrm{N})$ & (11) & (58) & \multirow[t]{2}{*}{ (69) } \\
\hline & & $15.9 \%$ & $84.1 \%$ & \\
\hline & \multirow[t]{2}{*}{$(\mathrm{N})$} & \multirow[t]{2}{*}{ (50) } & \multirow[t]{2}{*}{ (86) } & $(136)$ \\
\hline & & & & $71.3 \%$ \\
\hline
\end{tabular}

over chance. It was concluded that self-esteem is the best predictor of mobility grouping based on distance moved.

A major problem in geographic mobility research has been the need for an accurate definition of geographic mobility. The present study utilized distance moved and number of moves to define geographic mobility. Table IV-22 compares the predictive values of distance moved and number of moves as they were used in this study.

Entrees in Table IV-22 represent either Type I or effect sums of squares in columns two and five. Total sums of squares for each analysis is presented in columns three and six. Since each analysis of main effects was conducted once for distance moved and once for number of moves, it is possible to compare effect size for the two analyses. As an example, the significant self-esteem effect accounted for $14.5 \%$ of total 
TABLE IV-22

Predictive Values for Distance Moved

and Number of Moves

\begin{tabular}{lccc|ccc}
\hline & \multicolumn{2}{c}{ Distance Moved } & \multicolumn{3}{c}{ Number of Moves } \\
& Type I SS & SS & $\%$ & Type I SS & SS & $\%$ \\
\hline S.E. & 336.58 & 2313.82 & 14.5 & 197.40 & 2558.41 & 7.7 \\
EST & 459.33 & 5447.74 & 8.4 & 182.46 & 5702.58 & 3.2 \\
SCAT & 41.11 & 4126.18 & 1.0 & 7.20 & 4212.73 & 0.2 \\
FNE & 184.04 & 6418.76 & 2.9 & 28.93 & 6613.08 & 0.4 \\
\hline
\end{tabular}

variance in the distance moved analysis as compared to only $7.7 \%$ in the number of moves analysis. An examination of each variable in Table IV-22 reveals that effects were in all cases more pronounced when distance moved represented the independent variable. This supports the findings of Inbar (1976) and Kroger (1980). It was concluded that distance moved is a better method of defining geographic mobility when trying to predict S.E., EST, SCAT, and FNE scores.

\section{DISCUSSION}

The intent of this research was to better identify psychological variables, particularly sport specific psychological variables, associated with geographic mobility. Although theorists generally agree that a change of residence can have an adverse effect on the psychological development of children, there is little empirical information available. 
As evidenced in the test of Hypothesis I, high-mobile subjects scored significantly lower in self-esteem than low-mobile subjects. These results are in agreement with past research concerning the effects of geographic mobility on self-esteem. Global self-esteem was identified to be the best discriminator of high and low mobility groups through discriminant function analysis. This function correctly classified 97 of 136 subjects for a classification accuracy of $71.3 \%$.

Hypothesis II was supported when high-mobile subjects scored significantly lower in estimation than low-mobile subjects. High correlations between EST and global self-esteem $(r=.53+.41)$ have been achieved in previous studies (Sonstroem, 1978). The correlation obtained between self-esteem and EST in this study also proved to be significant $(r=.51)$. The emergence of physical estimation as a significant variable related to mobility helps justify research aimed at the effect of geographic mobility in a physical educational environment.

High-mobile students had significantly higher FNE scores than low-mobile students when distance moved was used to define mobility. FNE may be described as the result of accumulated consequences of participating in the process of socio-evaluative situations. The high-mobile child is repeatedly placed in different social environments where we might expect him to develop high FNE characteristics.

The SCAT did not prove to be a significant variable in this study. The study population may not have had enough competitive experience to make the SCAT sensitive enough to detect any changes caused by the moving experience. It is possible that replication of this study 
utilizing a sample restricted to athletes will produce significant differences in SCAT scores.

TABLE IV-23

Pearson $r$ Correlation Between Dependent Variables

(Distance Moved)

\begin{tabular}{|c|c|c|c|c|c|c|c|c|}
\hline & \multicolumn{4}{|c|}{ High-Mobile Group $(\mathrm{N}=69)$} & \multicolumn{4}{|c|}{ Low-Mobile Group ( $N=69)$} \\
\hline & S.E. & EST & SCAT & FNE & S.E. & EST & SCAT & FNE \\
\hline S.E. & 1.00 & 0.65 & -0.42 & -0.61 & 1.00 & 0.40 & -0.18 & -0.11 \\
\hline EST & --- & 1.00 & -0.65 & -0.59 & --- & 1.00 & -0.18 & -0.22 \\
\hline SCAT & $-\infty$ & $-\cdots$ & 1.00 & 0.46 & -- & ---- & 1.00 & 0.38 \\
\hline FNE & $-\infty$ & $-\infty$ & - & 1.00 & $-\cdots$ & --- & --- & 1.00 \\
\hline
\end{tabular}

Table IV-23 shows correlation coefficients between dependent variables for the high-mobile group scores and the low-mobile group scores. The significance of differences was tested by use of a z-transformation in reference to a normal distribution table (see Ferguson, 1966, pp. 187-88). The relationship between S.E. and EST was significantly greater in the high-mobile group $(r=0.65)$ compared to the low-mobile group $(r=0.40, p<.05)$. The difference between S.E. and FNE was significantly greater for the high-mobile group $(r=-0.61)$ compared to the low-mobile group $(r=-0.11, p<.001)$. Based on these analyses, it was concluded that lower levels of self-esteem are associated with poor conceptions of physical abilities and a fear of negative and social evaluation.

A significant difference in self-esteem scores between subjects at 
Fitch Junior High School and Cutler Junior High School, the two schools used in this study, is indicated in Table IV-2. It is possible that self-esteem scores may be influenced by the different school environments rather than by the effect of geographic mobility. However, the fact that $56.1 \%$ of the selected sample at Fitch Junior High School was placed in the high-mobile category, compared to $11.7 \%$ of the Cutler Junior High School sample, indicates that the between school difference in self-esteem may also be the result of the higher percentage of high-mobile students attending Fitch Junior High School. Since we cannot determine which variable was responsible for the difference in self-esteem scores, control of this factor is needed and recommended for future studies.

One of the problems with geographic mobility research has been finding the most accurate method of defining mobility. An attempt was made to compare the predictive values of distance moved and number of moves as methods of defining geographic mobility (see Table IV-22). The predictive value for each variable was substantially greater when distance moved was used as the definition of mobility.

The effects of geographic mobility on the self-esteem, EST, and FNE levels of junior high school students are evident. To what extent these results might apply to members of a restricted population, such as athletic team participants, awaits further investigation. By limiting the range of scores to be evaluated, very different results may be produced. Research aimed at the effect of geographic mobility on athletic participation and performance may prove to be interesting as well as enlightening. 


\section{PRACTICAL IMPLICATIONS}

It is hoped that parents, teachers, and coaches can better understand the problems facing children as they attempt to adjust to new environments. Children often view changing residences as a threatening experience. It may be possible to modify the effect of this experience through attitude adjustment. Although this study does not tell us how to avoid the negative effects of geographic mobility, evidence supporting the need for further research on this topic is provided.

This study has increased the knowledge concerning the identification of factors which are related to the experience of geographic mobility. As the relationships between variables associated with geographic mobility are identified, strategies designed to reduce its' effect can be formulated.

\section{RECOMMENDATIONS FOR FUTURE RESEARCH}

It is recommended that future studies should concentrate on distance of moves as a method of defining mobility. It appears to be a more accurate measure of geographic mobility both in research and theory. Also, standards for high and low mobility have been developed. Researchers should strive to be consistent in defining high and low mobility. Future studies might also attempt to control for the effects of family cohesion. Any negative effects of high geographic mobility could be counteracted by a highly supportive family environment and, as a result, could be an important variable in the geographic mobility construct. 
It has been determined that the high-mobile child has significantly different self-esteem, physical estimation, and fear of negative evaluation scores when distance of moves is used to define mobility. Replication of research utilizing these variables is suggested. The Sport Competion Anxiety Test failed to be a significant factor in this study. However, use of this instrument with a restricted population may alter these results. Since it is possible for high-mobility characteristics to effect athletic participation and performance, it is recommended that future studies explore the potential existence of these relationships. 


\section{BIBLIOGRAPHY}

AAHPER Youth Fitness Manual (1965). American Association of Health, Physical Education and Recreation, Washington, D.C.

Benson, G.P., Haycraft, J.L., Steyaert, J.P., \& Weigel, D.J. (1979). Mobility in sixth graders as related to achievement, adjustment, and socioeconomic status. Psychology in the Schools, 16, (3), 444-447.

Bernardo, P. (1979). Fear of Negative Evaluation as a Component of Competitive Stress Among Female College Basketball Players. Masters Thesis, University of Rhode Island.

Bills, R. (Undated). Index of Adjustment and Values. Manual. Auburn, Ala.: Alabama Polytechnic Institute.

Bow1by, J. (1980). Attachment and Loss: Vol. 3: Loss, Sadness, and Depression. New York: Basic Books.

Coopersmith, S. (1967). The Antecedents of Self-Esteem. San Francisco: Freeman.

Day, M. (1964). Comparison of military transient and non-transient elementary school children with respect to achievement and anxiety. Masters Thesis, University of Rhode Island.

Decennial Census, (1980). Neighborhood Statistics Program, Groton, Conn.

Erickson, E.H. (1950). Childhood and Society. New York: W.W. Norton and Co.

Ferguson, G. (1966). Statistical Analysis in Psychology and Education. Statistical Analysis in Psychology and Education. New York: McGraw-Hill.

Fitts, W.H. (1965). Tennessee Self-Concept Scale. Manual. Nashville, Tenn.: Tennessee Self-Concept Scale. Manual. Nashville, Tenn.: Counselor Recordings and Tests.

Fitts, W.H. (1972). The Self-Concept and Behavior: Overview and Supplement. Nashville, Tenn. Counselor Recordings and Tests.

Fleishman, E.A. (1964). The Structure and Measurement of Physical Fitness. Englewood Cliffs, N.J.: Prentice Hall.

Gergen, K.(1971). The Concept of Self. New York: Holt, Rinehart, \& Winston.

Groton City Directory (1977-78). New Haven, Conn.: Price and Lee Co.

Groton Public Schools (1985). Personal Communication with the Office of the Superintendent of Schools, Groton, Conn. 
Hellison, D.R. (1970). Physical Education and the Self-Attitude. Quest, $8,41-45$.

Holland, J.V., Kaplan, D.M., \& Davis, S.D. (1974). Interschool transfers: A mental health challenge. The Journal of School Health, 44, (2), 74-79.

Horney, K. (1950). Neurosis and Human Growth. New York: Norton Press.

Inbar, M. (1976). Social Science Frontiers: The Vulnerable Age Phenomenon. New York: Russell Sage Foundation.

James, W. (1950). Principles of Psychology, Vo1. 1. New York: Henry Holt.

Kliman, G. (1968). Psychological Emergencies of Childhood. New York: Grune and Stratton.

Kroger, J.E. (1980). Residential Mobility and self concept in adolescence. Adolescence, 15, (60), 967-977.

Lacey, C., \& Blane, D. (1979). Geographic mobility and school attainment: The confounding variables. Educational Research, 21, 200-206.

Landers, D.M. (1978). Motivation and performance: The role of arousal and attention. In W.F. Straub(Ed.), Sport Psychology: An analysis of athlete behavior. Ithaca, N.Y.: Mouvement Publications.

Mandler, G. \& Sarason, S.B. (1952). A study of anxiety and learning. Journal of Abnormal and Social Psychology, 47, 166-173.

Martens, R. (1977). Sport Competition Anxiety Test. Champaign, I11.: Human Kinetics Publishers.

Martens, R. \& Simon, J. (1976) Comparisons of three predictors of state anxiety in competitive situations. Research Quarterly, 47, 381-387.

Mead, G.H. (1934). Mind, Self and Society. Chicago: University of Chicago Press.

Morgan, W.P. (1977). Influence of chronic physical activity on selected psychological states and traits of police officers. Technical

Report. International Association of Chiefs of Police, Washington, D.C.

O'Brian, E.J. \& Epstein, S. (1974). Naturally occurring changes in self-esteem. Paper presented at the meeting of the American Psychological Association, New Orleans, La.

Pope, H.G., Ionescu-Pioggia, M., \& Yurgelun-Todd, D. (1983). Migration and manic-depressive illness. Comprehensive Psychology, 24, (2), 158-165. 
Rosenberg, M. (1963). The association between self-esteem and anxiety. Journal of Psychological Research, 1, 135-152.

Rosenberg, M. (1965). Society and the Adolescent Self-Image. Princeton, N.J.: Princeton University Press.

Rosenberg, M. (1979). Conceiving the Self. New York: Basic Books.

Rubin, Z. (1980). Childrens Friendships. Cambridge, Mass.: Harvard University Press.

Sonstroem, R.J. (1974). Attitiude testing examining certain psychological correlates of physical activity. Research Quarterly, 45, 93-103.

Sonstroem, R.J. (1975). Assessment of attitude toward physical activity and estimation of physical ability: Theoretical and applied considerations. Annual Meeting, American College of Sports Medicine, New Orleans, La.

Sonstroem, R.J. (1976). The validity of self-perceptions regarding physical and athletic ability. Medicine and Science in Sports, 8, 126-132.

Sonstroem, R.J.(1978). Physical estimation and attraction scales: Rationale and research. Medicine and Science in Sports, 10, (2), 97-102.

Sonstroem, R.J. (1982). Exercise and self-esteem: Recommendations for expository research. Quest, 33, (2), 124-139.

Sonstroem, R.J. \& Kampper, R.P. (1980). Prediction of athletic participation in middle school males. Research Quarter 1y for Exercise and Sports, 51, 685-694.

Spielberger, C.D. (1966). Theory and research on anxiety. In C.D. Spielberger (Ed.), Anxiety and Behavior. New York: Academic Press.

Spielberger, C.D. (1972). Conceptual and methodological issues in anxiety research. In C.D. Spielberger (Ed.), Current Trends in Theory and Research Vo1. 1, New York: Academic Press.

Spielberger, C.D., Gorsuch, R.L., \& Lushene, R.E. (1970). Manual for the State-Trait Anxiety Inventory. Palo Alto, California: Consulting Psychologists Press.

Switzer, R. (1961). The effect of family moves on children. Mental Hygiene, 45, 528-536.

U.S. Bureau of the Census (1982). Current Population Reports, Washington, D.C.: U.S. Government Printing Office. 
Watson, D. \& Friend, R.M. (1969). Measurement of social-evaluative anxiety. Journal of Consulting and Clinical Psychology, 33, $448-457$.

Wylie, R.C. (1974). The Self-Concept (Vol. 1). Lincoln, Nebraska: University of Nebraska Press. 


\section{ATTITUDE QUESTIONNAIRE}

The statements in this booklet are to help you describe yourself asyou see yourself. Remember, there are no right or wrong answers. Please respond to each question as it applies to you. Circle a 1 underneath the question if you strongly disagree with the statement, circle a 2 if you disagree, circle a 3 if you agree, and circle a 4 if you strongly agree with the statement.

1. I feel I'm a person of worth, at least on an equal basis with others. Strongly Disagree / Disagree / Agree / Strong1y Agree

$$
\begin{array}{lllll}
1 & 2 & 3 & 4
\end{array}
$$

2. I feel I have a number of good qualities. $\begin{array}{ccccc}\text { Strongly Disagree / Disagree / Agree / } & \text { Strongly Agree } \\ 1 & 2 & 3 & 4\end{array}$

3. All in a1l, I an inclined to feel that I'm a failure. Strongly Disagree / Disagree / Agree / Strongly Agree

4. I am able to do things as well as most other people. Strong1y Disagree / Disagree / Agree / Strongly Agree

$$
\begin{array}{lllll}
1 & 2 & 3 & 4
\end{array}
$$

5. I feel I do not have much to be proud of.

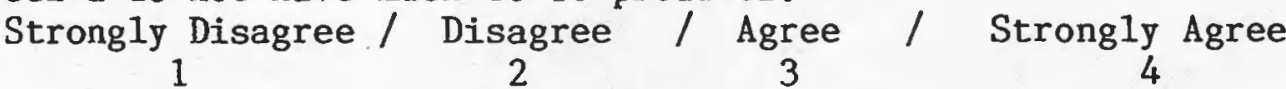

6. I take a positive attitude toward myself. Strongly Disagree / Disagree / $\underset{1}{\text { Agree }} /$ Strong1y Agree

7. On the whole, I am satisfied with myself. Strongly Disagree / Disagree / Agree / Strongly Agree

8. I wish I could have more respect for myself. Strong1y Disagree / Disagree / $\underset{1}{\operatorname{Agree}} / \mathrm{3}$ Strongly Agree

9. I certainly feel useless at times. $\underset{1}{\text { Strongly Disagree / Disagree / }} \underset{2}{\text { Agree }} / \underset{3}{\text { Strong1y Agree }}$

10. At times I think I am no good at all. Strongly Disagree / Disagree / Agree 1 


\section{APPENDIX B}

\section{ATTITUDE QUESTIONNAIRE}

The statements below reflect certain attitudes and interests of persons. Read each statement and decide whether it is true or false as applied to you. Indicate your answer by circling a $T$ (for true) of an $F$ (for false) to the left of each item. In some cases you may have difficulty deciding which response is best, but please make some decision and answer every item. Even if an item asks about things you haven't experienced, answer it as best you can on the basis of what you have heard, seen, or read. -For items such as \#2, compare yourself with members of your own sex. Girls compare yourselves with other girls, boys compare yourselves with other boys.

$\mathrm{T} \quad \mathrm{F}$ 1. Most of my friends work harder than $\mathrm{I}$ do.

T F 2. My body is strong and muscular compared to other boys/girls my age.

$\mathrm{T} F$ 3. I am in better physical condition than most boys/girls my age.

T F 4. I am quite limber and agile compared to others my age.

$\mathrm{T}$ F 5. I just don't have the coordination necessary to look like a graceful skier.

T F 6. I am better coordinated than most people I know.

$\mathrm{T} \quad \mathrm{F}$ 7. I am a good deal stronger than most of my friends.

T F 8. Compared to other people I an somewhat clumsy.

T F 9. I an stronger than a good many of my friends.

T F 10. Most people I know think I have very good physical skills.

T F 11. My friends seem to be more physically active than I am.

T F 12. I doubt that I could ever get into good physical condition.

$\mathrm{T} F$ 13. My legs have as much spring as those of champion high jumpers.

$\mathrm{T} F$ 14. If I wanted to, I could become an excellent tennis player.

$\mathrm{T} F$ 15. It is difficult for me to catch a thrown bal1.

$\mathrm{T} \quad \mathrm{F}$ 16. With a fair amount of practice I could maintain a high bowling average. 
T F 17. I can run faster than most of my friends.

T F 18. With practice I could become a very good golfer.

T F 19. I could do better at long distance hiking than the average boy/girl my age.

T F 20. I exhibit a Eair amount of leadership in a sports situation.

T F 21. I lack confidence in performing physical activities.

$\mathrm{T} F$ 22. Even with practice I doubt that I could learn to do a handstand wel1.

$\mathrm{T}$ F 23. I can run for longer distances than most boys/girls my age.

T F 24. I'm a natural athlete.

T F 25. I have a strong throwing arm for baseball or softball.

$\mathrm{T} F$ 26. It would be very difficult for me to learn to do a back dive.

T F 27. I an well-equipped to excel at physical activities.

$\mathrm{T} \quad \mathrm{F}$ 28. Even with practice I doubt that I could ever learn to do a cartwheel well.

T F 29. Probably I could get into good physical condition faster than most fellows/girls my age.

T F 30. I often doubt my physical abilities.

$\mathrm{T} \quad \mathrm{F}$ 31. I'm not very good at most physical skills.

T F 32. Poor timing handicaps me in certain physical activities.

$\mathrm{T} \quad \mathrm{F}$ 33. I am a natural leader in sport activities. 


\section{APPENDIX C \\ ILLINOIS COMPETITION QUESTIONNAIRE \\ (Form A)}

Directions: Below are some statements about how persons feel when they compete in sports and games. Read each statement and decide if you HARDLY-EVER, or SOMETIMES, or OFTEN feel this way when you compete in sports and games. If your choice is HARDLY-EVER, blacken the square labeled A; if your choice is SOMETIMES, blacken the square labeled B, and if your choice is OFTEN, blacken the square labeled C. There are no right or wrong answers. Do not spend too much time on any one statement. Remember to -choose the word that describes how you usually feel when competing in sports and games.

1. Competing against others is socially enjoyable.

Hardly-ever Sometimes Often

2. Before I compete, I feel uneasy.

A I

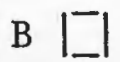

c 回

3. Before I compete, I worry about not performing well.
A I
B [
c 回
A

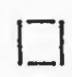
в II
c II

4. I am a good sportsman when I compete.
A<smiles>C1CC2CCC12</smiles>
B II
c 回

5. When I compete, I worry about making mistakes.
A
I
в II
C I I

6. Before I compete, I am calm.

A

B II

C I

7. Setting a goal is important when competing.

A I

B II

c I

8. Before I compete, I get a queasy feeling in my stomach.
A I
B I
C 回

9. Just before competing, I notice my heart beats faster than usual.

10. I like to compete in games that demand considerable physical

A

B II

c I energy.

11. Before I compete, I feel relaxed.

A I

B II

c I

12. Before I compete, I am nervous.

13. Team sports are more exiting than individual sports.

A I

B II

A 回

B II

A II

B 回
C II

C 回

c I 


\section{Hardly-ever Sometimes Often}

14. I get nervous wanting to start the game.

A

B II

C II

15. Before I compete, I usually get up tight.

A I

в I

C I 


\section{APPENDIX D}

\section{GENERAL FEELINGS QUESTIONNAIRE}

(FNE)

Directions: Below are some statements about how persons feel when they are in certain situations. Read each statement and decide if the statement is generally true or false about yourself. If the statement is TRUE, circle T; if the statement is FALSE, circle F. Please remember that there are no right or wrong answers and that your responses are strictly confidential. Do not spend too much time on any one statement. Remember, your answers should describe how you usually feel in many different situations.

T F 1. I rarely worry about seeming foolish to others.

T F 2. I worry about what people will think of me even when I know it doesn't make any difference.

$\mathrm{T}$ F 3. I become tense and jittery if I know someone is sizing me up.

T F 4. I am unconcerned even if I know people are forming an unfavorable opinion of me.

T F 5. I feel very upset when I commit some social error.

T F 6. The opinions that important people have of me cause me little concern.

T F 7. I am often afraid that I may look ridiculous or make a fool of myself.

T F 8. I react very little when other people disapprove of me.

T F 9. I am frequently afraid of other people noticing my shortcomings.

T F 10. The disapproval of others would have little effect on me.

T F 11. If someone is evaluating me, I tend to expect the worst.

T F 12. I rarely worry about what kind of impression I am making on someone.

T F 13. I am afraid that others will not approve of me.

T F 14. I am afraid that people will find fault with me.

T F 15. Other people's opinions do not bother me.

T F 16. I am not necessarily upset if I do not please someone. 
T F 17. When I am talking to someone, I worry about what they may be thinking about me.

$\mathrm{T} \quad \mathrm{F}$ 18. I feel that you can't help making social errors sometimes, so why worry about it.

$\mathrm{T} \quad \mathrm{F}$ 19. I am usually worried about what kind of impression I make.

T F 20. I worry a lot about what my superiors think of me.

T F 21. If $\mathrm{I}$ know someone is judging me, it has little effect on me.

T F 22. I worry that others will think I am not worthwhile.

T F 23. I worry very little about what others may think of me.

T F 24. Sometimes I think I am too concerned with what other people think of me.

T F 25. I often worry that I will say or do the wrong things.

T F 26. I am often indifferent to the opinions others have of me.

T F 27. I am usually confident that others will have a favorable impression of me.

$\mathrm{T}$ F 28. I often worry that people who are important to me won't think very much of me.

T F 29. I brood about the opinions my friends have about me.

$\mathrm{T} \quad \mathrm{F}$ 30. I become tense and jittery if I know I am being judged by my superiors. 
APPENDIX E

GEOGRAPHIC REGIONS DEFINED (INBAR, 1976)

1. New England and Middle Atlantic States (Maine, New Hampshire, Vermont, Massachusetts, Rhode Island, Connecticut, New York, New Jersey, Pennsylvania).

2. East and West North Central States (Ohio, Indiana, Illinois, Michigan, Wisconson, Minnesota, Iowa, Missouri, North Dakota, South Dakota, Nebraska, Kansas).

3. South Atlantic, East South Central and West South Central States (Delaware, Maryland, District of Columbia, Virginia, West Virginia, North Carolina, South Carolina, Georgia, Florida, Kentucky, Tennessee, Alabama, Mississippi, Arkansas, Louisiana, Oklahoma, Texas).

4. Mountain States (Montana, Idaho, Wyoming, Colorado, New Mexico, Arizona, Utah, Nevada).

5. Pacific States (Washington, Oregon, California, Hawaii, Alaska).

6. United States Possessions (Puerto Rico, Guam, etc.), and Foreign. 


\section{APPENDIX F}

DISTANCE OF MOVES CALCULATIONS

Distance of each move will be given a weight according to the scale below (Kroger, 1980). For each subject, the total distance moved will be computed according to the following formula:

$$
\begin{aligned}
\text { Distance of move total }=\text { The sum of }(\mathrm{ab}) \quad \text { where } \mathrm{a}= & \begin{array}{r}
\text { number of } \mathrm{J} \\
\text { type moves }
\end{array} \\
\mathrm{b} & =\text { type } \mathrm{J} \text { weight }
\end{aligned}
$$

DISTANCE OF MOVES CODE

\begin{tabular}{clc}
\hline Type J & \multicolumn{1}{c}{ Type Name } & Type Weight \\
\hline 1 & Intracommunity & 1 \\
3 & Intrastate & 3 \\
4 & Intraregion (Contiguous State) & 4 \\
5 & Intraregion (Non-Contiguous State) & 5 \\
6 & Intranation (Contiguous State) & 6 \\
7 & Intranation (Non-Contiguous State) & 7 \\
& International &
\end{tabular}


APPENDIX G

STUDENT INFORMED CONSENT FORM

You are being asked to answer some questions on the following pages. The purpose of these questions is to survey attitudes which adolescents have about themselves and about physical activity. In giving us your honest answers you will be helping us learn more about a11 adolescents. It should be emphasized that there are no right or wrong answers. Your responsibility is to answer the questions honestly as they apply to you.

Results of these questionnaires will remain strictly confidential. All data will be coded and will not be identifiable by name. Participation in this survey is completely voluntary and you may refuse to complete the questionnaire at any time.

\section{Voluntary Consent}

The purpose of my participation in this survey has been explained to me. I freely consent to participate. I understand that I am not required to participate and that I may stop participation at any time. 
APPENDIX H

PARENTAL INFORMED CONSENT FORM

Your child has been randomly selected to participate in a research study designed to assess the attitudes of adolescents toward themselves and toward physical activity. An additional purpose of this study is to examine the effect of having lived in various areas of the country on the above variables. Student participation will consist of completing a paper and pencil inventory requiring approximately thirty minutes of time.

Results of this test will remain strictly confidential. All data will be coded and will not be identifiable by name. Participation in the survey is completely voluntary and your child may refuse to complete the questionnaire at any time. If you have any questions regarding this study, feel free to contact Mr. William LaFleur at Cutler Junior High School or Ms. Lorraine White at Fitch Junior High School. Results of the study may be obtained from the guidance departments at the above mentioned schools.

Parental Consent

I understand the purposes and nature of this study. I agree to allow my child to be a part of this investigation. 